\title{
The Light Microscopy Module: An On-Orbit Multi-User Microscope Facility
}

Susan M. Motil and John H. Snead

Glenn Research Center, Cleveland, Ohio 
The NASA STI Program Office . . . in Profile

Since its founding, NASA has been dedicated to the advancement of aeronautics and space science. The NASA Scientific and Technical Information (STI) Program Office plays a key part in helping NASA maintain this important role.

The NASA STI Program Office is operated by Langley Research Center, the Lead Center for NASA's scientific and technical information. The NASA STI Program Office provides access to the NASA STI Database, the largest collection of aeronautical and space science STI in the world. The Program Office is also NASA's institutional mechanism for disseminating the results of its research and development activities. These results are published by NASA in the NASA STI Report Series, which includes the following report types:

- TECHNICAL PUBLICATION. Reports of completed research or a major significant phase of research that present the results of NASA programs and include extensive data or theoretical analysis. Includes compilations of significant scientific and technical data and information deemed to be of continuing reference value. NASA's counterpart of peerreviewed formal professional papers but has less stringent limitations on manuscript length and extent of graphic presentations.

- TECHNICAL MEMORANDUM. Scientific and technical findings that are preliminary or of specialized interest, e.g., quick release reports, working papers, and bibliographies that contain minimal annotation. Does not contain extensive analysis.

- CONTRACTOR REPORT. Scientific and technical findings by NASA-sponsored contractors and grantees.
- CONFERENCE PUBLICATION. Collected papers from scientific and technical conferences, symposia, seminars, or other meetings sponsored or cosponsored by NASA.

- SPECIAL PUBLICATION. Scientific, technical, or historical information from NASA programs, projects, and missions, often concerned with subjects having substantial public interest.

- TECHNICAL TRANSLATION. Englishlanguage translations of foreign scientific and technical material pertinent to NASA's mission.

Specialized services that complement the STI Program Office's diverse offerings include creating custom thesauri, building customized data bases, organizing and publishing research results ... even providing videos.

For more information about the NASA STI Program Office, see the following:

- Access the NASA STI Program Home Page at http://www.sti.nasa.gov

- E-mail your question via the Internet to help@sti.nasa.gov

- Fax your question to the NASA Access Help Desk at 301-621-0134

- Telephone the NASA Access Help Desk at $301-621-0390$

- Write to:

NASA Access Help Desk

NASA Center for AeroSpace Information 7121 Standard Drive

Hanover, MD 21076 
NASA/TM-2002-211355

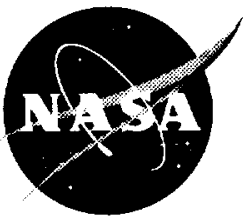

\section{The Light Microscopy Module: An On-Orbit Multi-User Microscope Facility}

Susan M. Motil and John H. Snead

Glenn Research Center, Cleveland, Ohio

Prepared for the

International Space Station Utilization-2001

sponsored by the American Institute of Aeronautics and Astronautics

Cape Canaveral, Florida, October 15-18, 2001

National Aeronautics and

Space Administration

Glenn Research Center 


\section{Acknowledgments}

We gratefully acknowledge the support provided by Michael P. Doherty of the NASA Glenn Research Center. His attention to detail and unpublished design documentation was invaluable. Also, we acknowledge the support of Edward A. Hovenac and the Northrup-Grumman LMM engineering team. Northrup-Grumman is the developer of LMM supported by the Microgravity Science Division under the Microgravity Research, Development, and Operations Contract, NAS3-99155.

This report contains preliminary findings, subject to revision as analysis proceeds.

Available from

NASA Center for Aerospace Information 7121 Standard Drive Hanover, MD 21076

National Technical Information Service 5285 Port Royal Road Springfield, VA 22100 


\title{
THE LIGHT MICROSCOPY MODULE: AN ON-ORBIT MULTI-USER MICROSCOPE FACILITY
}

\author{
Susan M. Motil and John H. Snead \\ National Aeronautics and Space Administration \\ Glenn Research Center \\ Cleveland, Ohio 44135
}

\begin{abstract}
The Light Microscopy Module (LMM) is planned as a remotely controllable on-orbit microscope subrack facility, allowing flexible scheduling and operation of fluids and biology experiments within the Fluids and Combustion Facility (FCF) Fluids Integrated Rack (FIR) on the International Space Station (ISS). The LMM will be the first integrated payload with the FIR to conduct four fluid physics experiments. A description of the LMM diagnostic capabilities, including video microscopy, interferometry, laser tweezers, confocal, and spectrophotometry, will be provided.
\end{abstract}

\section{INTRODUCTION}

Within the FCF Fluids Integrated Rack (FIR), an initial complement of four fluid physics experiments will utilize the LMM instrument which is built around a light microscope. These experiments are the "Constrained Vapor Bubble" experiment (Peter C. Wayner of Rensselaer Polytechnic Institute), the "Physics of Hard Spheres Experiment-2" (Paul M. Chaikin of Princeton University), the "Physics of Colloids in Space-2" experiment (David A. Weitz of Harvard University), and the "Low Volume Fraction Entropically Driven Colloidal Assembly" experiment (Arjun G. Yodh of the University of Pennsylvania). The first experiment investigates heat conductance in microgravity as a function of liquid volume and heat flow rate to determine, in detail, the transport process characteristics in a curved liquid film. The other three experiments investigate various complementary aspects of the nucleation, growth, structure, and properties of colloidal crystals in microgravity and the effects of micromanipulation upon their properties.

The Light Microscopy Module (LMM) is a sophisticated, modified Leica RXA commercial research imaging light microscope with laser diagnostics hardware and interfaces to conduct on-orbit colloid and fluid physics experiments, creating a oneof-a-kind, state-of-the-art microscopic research facility. The LMM will provide imaging techniques of color video microscopy, bright field, dark field. phase contrast, differential interference contrast (DIC) to observe sample features including basic structures and dynamics: spectrophotometry to measure colloidal crystal photonic properties; and confocal microscopy to provide enhanced three-dimensional visualization of colloidal structures all combined in a single configuration. Integrated with the diagnostics are single-trap scanning laser tweezers, to perform sample particle manipulation and patterning.

A versatile, modular instrument attractive to future fluids, colloids, and biological experiments, the LMM is planned for operation within the FIR on the U.S. Lab for 25 months. Operations involve the logistics of transporting the LMM and the Principal Investigator (PI) sample cell hardware to the ISS, set-up and checkout of the flight hardware, performance of the science mission, maintenance, and return of the flight hardware from orbit. All of these elements will directly affect the level of LMM utilization, its design, and ultimate appeal to the science community.

\section{LMM UTILIZATION}

The LMM design is accessible, modular, and a flexible assembly to permit on-orbit reconfiguration and maintenance, while minimizing up-and-down-mass stowage. The instrument's flexibility will allow the facility to support future investigators.

The LMM will be integrated into the Fluids Integrated Rack in the U.S. Laboratory on the International Space Station (ISS), as a sub-rack payload, enhancing the FIR's diagnostic capabilities as a carrier. ${ }^{1.2}$ The LMM module will be attached to the FIR's optics bench, and will receive power, communications, air and water 
cooling, vacuum exhaust, avionics, image processing, data storage, and additional science diagnostic hardware through the FIR rack, as shown in Figure 1. The LMM will be installed on-orbit, and remain in the FIR for a period of 25 months performing four separate fluid physics experiments.
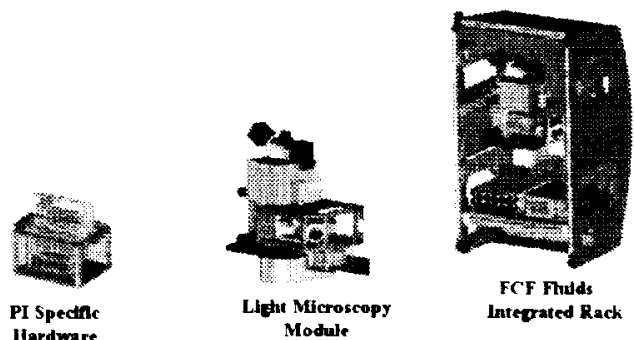

Figure 1: Integrated LMM and FIR concept

\section{Constrained Vapor Bubble}

The Constrained Vapor Bubble (CVB) experiment is the first experiment to be performed on-orbit within the LMM. The objective of this experiment is to better understand the physics of evaporation and condensation as they affect the heat transfer processes in a constrained vapor bubble heat exchanger. The thermophysical principles underlying change-of-phase heat transfer systems controlled by interfacial phenomena under microgravity conditions are not well understood. As a result, related passive engineering systems for spacecraft have not been optimized. The CVB experiment proposes basic experimental and theoretical studies of the non-isothermal constrained vapor bubble (CVB) under microgravity conditions to help remedy this undesirable situation.

The CVB heat exchanger consists of a small container, enclosed and partially filled with a liquid. When a temperature difference is applied to the ends of the CVB heat exchanger, evaporation occurs at the hot end and condensation at the cold end, resulting in a very effective heat transfer device with great potential in space applications. ${ }^{3.4}$

The microscopic intermolecular force (pressure) field, which is a function of the liquid film thickness profile, will be measured using microcomputer enhanced video microscopy based on the interferometry temperature field obtained using thermal sensors in the cell wall. This multi-faceted experiment is a basic scientific study in interfacial phenomena, microgravity fluid physics, and thermodynamics; and thermal transport. The research naturally leads to the development of a passive heat exchanger optimized for microgravity conditions.
The Principal Investigator seeks to determine the stability, fluid flow characteristics, the average heat transfer coefficient in the evaporator, and the heat conductance of the CVB as a function of the heat flow rate and vapor volume. The immediate goal is to detail the characteristics of the transport processes in the curved liquid film. ${ }^{6,7}$ The local conditions under which cavitation and instability occur with the formation of a dry region will be determined as a function of heat flux, film thickness, and stress. High fluxes and relatively large systems with small capillary pressures will be emphasized. Both completely wetting (Pentane) and partially wetting (Ethanol) fluids will be studied and compared. Vapor bubble lengths will vary at $20 \mathrm{~mm}$, $30 \mathrm{~mm}$ and $40 \mathrm{~mm}$ for pentane, and $25 \mathrm{~mm}$ for ethanol.

\section{Physics of Hard Spheres Experiment - 2}

The experiment objective for the Physics of Hard Spheres Experiment -2 ( $\left.\mathrm{PH}^{\mathrm{A}} \mathrm{SE}-2\right)$ microgravity experiment is to further investigate the nucleation, growth, structure, dynamics, and rheology of colloidal crystals. ${ }^{8}$ The PI's seek to observe the effect of hard sphere parametric conditions on the equilibrium phase diagram, and how colloidal systems respond to applied fields. ${ }^{9.10} \mathrm{PH}^{\mathrm{A}} \mathrm{SE}-2$ consists of microscopy, microscopic and mesoscopic manipulation and control of colloidal samples to probe the essential features of the hard sphere disorder-order transition, and the properties of the ordered solid phase that results. Samples of various volume fractions will permit measurements from the disordered fluid phase, through the coexistence region. into the fully crystalline solid, and beyond into a glasslike phase. Achieving these measurement will require application of external fields (temperature gradients, periodic pattern imposition) and force application (optical tweezers). The dispersions will consist of colloidal hard spheres, in the 0.65 to $1.0 \mu \mathrm{m}$ diameter range, with controlled polydispersity: consisting of polymethyl-methacrylate in an index-matched fluid.

Microscopy will allow for the observation of the position of individual colloidal particles and thus the determination of local crystalline or liquid structure, defect structure, observation of nucleation and growth of individual crystallites, the spontaneous formation of dendrites, the effect of periodic and other imposed patterns, field induced local melting and freezing, and dynamics of liquid-crystal, liquid-glass and solid-glass interfaces.

The applied fields will allow for controlled nucleation and growth, induced metastable phases, susceptibility to electric fields, and rheology measurements. The large 
number of samples to be tested has lead the LMM to develop a platen containing up to 120 sample cells, as shown in Figure 2.

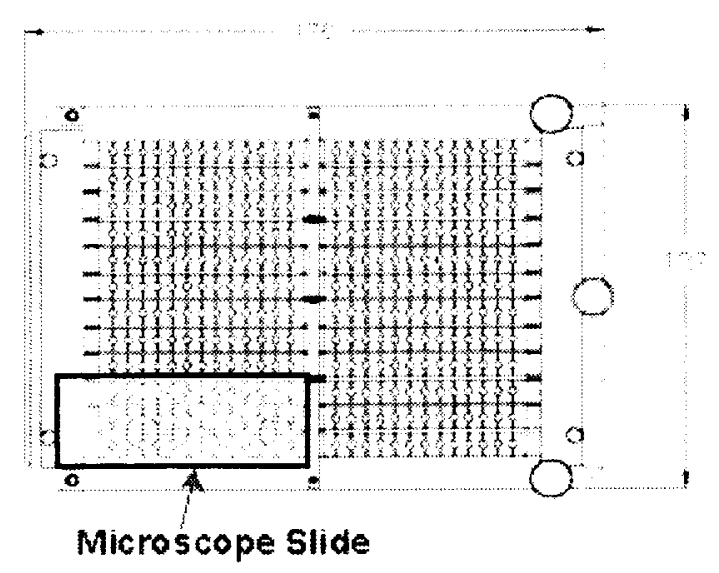

Figure 2: LMM sample platen

The platen consists of rows of sample cells attached to the underside of a microscope platen. About $50 \mu \mathrm{l}$ of sample fluid is contained in each sample cell (Figure 3 ). This design allows the contents of many cells to be examined under a variety of conditions before a crew member is needed to exchange platens.

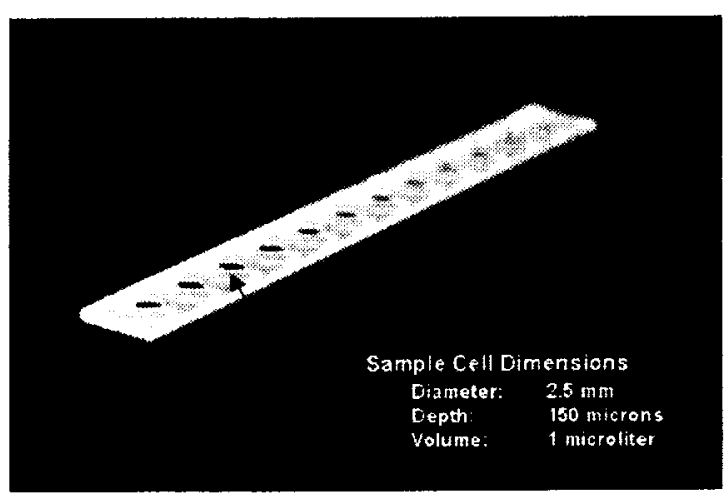

Figure 3: LMM sample cells

\section{Physics of Colloids in Space - 2}

The goals of Physics of Colloids in Space - 2 (PCS-2) experiment are twofold: to carry out further investigation of critical, fundamental problems in colloid science, and to fully develop the evolving field of "colloid engineering," to create materials with novel properties using colloidal particles as the precursors. This experiment is a follow-on to the Physics of Colloids in Space (PCS), which is currently operating on the International Space Station. ${ }^{11}$
PCS-2 will focus on two classes of colloidal samples. The first is binary alloys. These contain a mixture of two different sized acrylic spheres, ranging from $10 \mathrm{~nm}$ to $5 \mu \mathrm{m}$, dispersed in a liquid. The choice of size ratio, concentration ratio, and total particle volume fraction will be based on the results from PCS and prior Glovebox experiments. ${ }^{12.13 .14}$ The second set of samples will be a mixture of colloidal particles with polymers. The addition of the polymers induces a controllable attractive force due to depletion ${ }^{15}$ between the colloidal particles. This attractive force facilitates the formation of other structures. In addition, the presence of an attractive force induces new phase behavior in the colloidal suspensions. $^{16.17}$

The LMM optical microscope will allow the properties of the materials to be measured, and allow a degree of proactive control over the structures and properties of the materials produced. The microscope will be equipped to allow direct visualization of the particles in real space, using both bright field and differential interference contrast (DIC) imaging, as well as fluorescent imaging. The microscope will also be equipped with laser tweezers to manipulate the structures. In addition, there will be confocal microscopy to allow strongly scattering samples to be studied and to provide $3 \mathrm{D}$ real-space information. Because of the very small sample volumes required, the LMM will be able to examine up to 120 samples, allowing the requisite sample variation to be achieved. Sample cell development is identical to the $\mathrm{PH}^{\mathrm{A}} \mathrm{SE}-2$ experiment, and shown in Figures 2 and 3.

\section{Low Volume Fraction Entropically Driven Colloidal Assembly Experiment}

The Low Volume Fraction Entropically Driven Colloidal Assembly (LФCA) experiment aims to create new colloidal crystalline materials, study the assembly of these materials, ${ }^{18}$ measure their optical properties, and then solidify the resulting structures so that they can be brought back and studied on earth. The experiment consists of sample preparation, microscopic observations of crystal growth, characterization of samples, and sample solidification. The latter two parts will only be carried out on selected samples. Samples will consist of colloidal particles with diameters ranging from 0.4 to 3.0 microns suspended in water or other organic fluids. The particles will be polymer-based spheres such as PMMA, polystyrene (PS), silica with or without embedded fluorophores, semiconductors, or novel polymer-based spheres that have hollow interiors or interiors filled with magnetic or metal grains. The small species can be a polymer (e.g., polystyrene 
polymer), a micelle (e.g., surfactant micelles), a dendrimer, or even a very small particle.

Crystallization of large spheres occurs in the low volume fraction binary suspensions by the attractive particle interactions brought about by the depletion effect, thus creating conditions for growth more closely resembling that which happens on the atomic and molecular scale. Yodh's interest in investigating colloidal crystal growth and formation includes the creation of novel structures and photonic materials (e.g., Ultralow-noise light sources, switches, and strong ceramics) of industrial importance. ${ }^{19.20}$

These samples are contained in the same configuration as shown in Figures 2 and 3. A grating template will be bonded to the coverslip, which biases the growth process so that crystals with random stacking are not formed. The sample volumes will be $\sim 50$ microliters or less. At the beginning of the experiment, the samples will be homogenized and the evolution of crystal structures will be observed using the LMM microscope. Crystal growth processes will be monitored and images acquired and stored. This will enable the determination of crystal structure and crystal quality, and correlate these observations with sample volume fractions. In aqueous suspensions, the solidification process is facilitated by UV light-induced polymer gelation. In organic solvents, a similar procedure will be developed. Generally, the materials that will be synthesized cannot be made on earth as a result of sedimentation. Finally, it is anticipated that the solidified structures will survive re-entry to earth's gravitational field, and their optical, magnetic, and electrical properties can be further studied in detail upon return.

\section{LMM CAPABILITIES}

The LMM flight unit features a modified commercial off-the-shelf (COTS) Leica RXA microscope, which is enhanced to operate automatically with some interaction from the ground support staff or the astronaut crew. The microscope is modified and enhanced to provide additional capabilities including: 1) Video microscopy to record sample features including basic structures and crystal growth dynamics, 2) Interferometry, to measure vapor bubble thin film thickness, 3) Laser tweezers for sample particle manipulation and patterning, 4) Confocal microscopy to provide threedimensional visualization of sample structures, and 5) spectrophotometry to measure photonic properties.

The imaging techniques of high resolution color video microscopy, bright field, dark field, phase contrast, differential interference contrast (DIC), fluorescence, spectrophotometry, and confocal microscopy are combined in a single configuration. An experimenter can choose from six (6) objective lenses of different magnifications and NA to achieve the required science data. This suite of measurements allows a very broad characterization of fluids, colloids, and two-phase media, including biological samples. Sample manipulation technique is integrated with the microscope's single-trap scanning laser tweezers. The LMM utilizes cameras and light sources provided by the FIR to accomplish these imaging techniques.

The LMM provides containment for fluids and shatterable materials. Essential components include an Auxiliary Fluids Container (AFC), which will be attached to the microscope, an Equipment Transfer Module (ETM) that will attach to the AFC, and the microscope itself, as shown in Figure 4. In general, PI experiment samples will be launched and transported in the ETM, and then the ETM will be attached to the AFC. A crewmember will use gloves attached to the AFC gloveports, to remove the PI experiments from the ETM, and place the samples on the microscope stage. After the sample has been positioned, the remote operation of the microscope, and processing of the samples can begin.

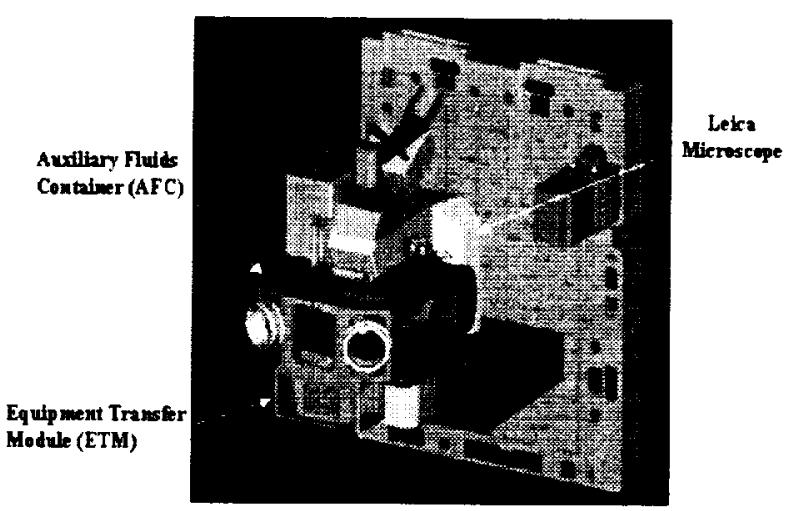

Figure 4: Integrated microscope, AFC, and ETM

The crew will need to set up the system in the LMM/FIR, reconfigure the LMM, and perform on-orbit maintenance. The ability to modify system parameters to expand the science investigation after early data is analyzed will be a design feature. In addition, LMM will have the ability to have its hardware reconfigured on-orbit to accommodate the various experiments.

\section{Video Microscopy}

Video microscopy ${ }^{21}$ will be performed via transillumination imaging techniques already resident within the Leica RXA microscope itself, namely, bright field, 
dark field, phase contrast, and differential interference contrast (DIC). A variety of condenser apertures, objectives, and prisms are required to support these techniques, but the Leica RXA comes well suited for the task. Optical microscopy of colloidal suspensions, will be performed using the four transillumination techniques. 15,22

The microscope will be configured to have a 0.9 Numerical Aperture (NA) condenser and microscope objectives up to $100 \mathrm{x}$ and $1.4 \mathrm{NA}$ (oil immersion) to support the required transillumination techniques. The light source for Köhler illumination is to be provided by an FCFprovided Metal Halide Lamp.' Images, such as those shown in Figure 5, will be captured by the FCF provided Toshiba color analog camera on the microscope's multi-port imaging head and subsequently downlinked for data processing.

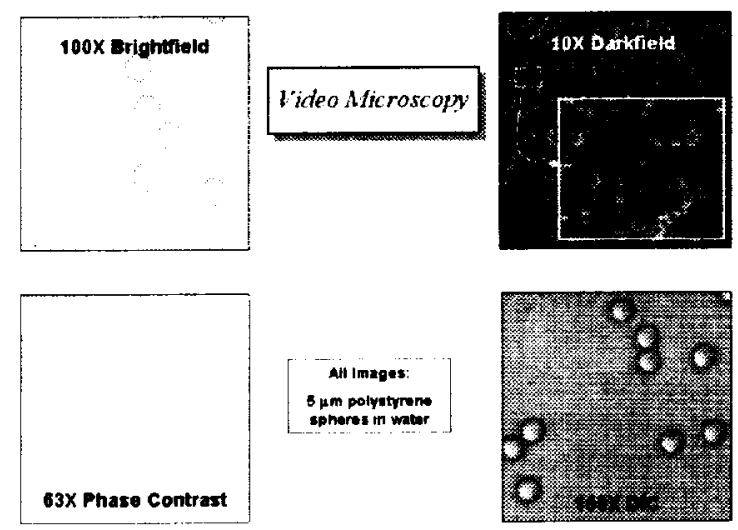

Figure 5: Microscope images of $5 \mu \mathrm{m}$ polystyrene spheres

\section{$\underline{\text { Interferometry }}$}

To determine the CVB bubble shape, calculation of the film curvature is required. Interferometry will be performed to measure the thickness of the liquid film utilizing a $50 \mathrm{x}$ objective. The light source in epi-illumination provides the required wavelengths to create the interference fringes. The light passes through the liquid and partially reflects at all interfaces, including the glass-liquid interface and liquid-vapor interface. The light from the two reflections interferes to form fringes that represent an increase in fluid thickness of half the wavelength of light for each bright and dark pair, as shown in Figure 6. The color analog camera on the multi-port imaging head will capture the images for downlinking and processing. Analyzing the interferometry images will yield a film thickness profile.

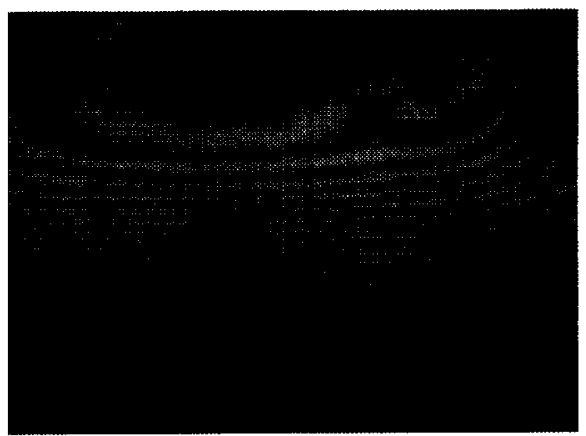

Figure 6: CVB bubble image at $435 \mathrm{~nm}$

The derivative of the thickness gives the curvature profile, and therefore the pressure field for flow in the liquid film. The thickness will be measured at multiple axial positions along the cuvette.

\section{$\underline{\text { Laser Tweezers }}$}

A laser tweezer system will be included in the LMM diagnostic package. Optical tweezers use a highly focused laser beam to trap a small $(\sim 1 \mathrm{~mm})$ off-index particle. $\mathrm{PH}^{\mathrm{A}} \mathrm{SE}-2$ and $\mathrm{PCS}-2$ will utilize the tweezers to create an array of optical traps to control a specific colloidal crystal structure and study the microrheological properties of the colloidal crystal.

Laser tweezers will be implemented using a custombuilt system based upon a 1064nm Nd:YAG laser, beam focusing optics, and two acousto-optic deflectors to steer the trap within the field of view of the microscope. Laser tweezers is simply the trapping of a colloidal particle using radiation pressure by focusing a laser beam through a high-numerical aperture lens and striking the particle. The LMM microscope's reflected light turret will contain a dichroic mirror to reflect the $1064 \mathrm{~nm}$ light down to the sample and simultaneously pass visible light in trans-illumination up to the color analog camera on the multi-port imaging head, thereby, allowing both the tweezer beam and the surrounding colloidal crystal to be imaged.

The laser tweezers have two elements of control. Changing the output laser intensity via commands to the laser controller varies the trapping force. The scanning trap position is controlled with two-axis acousto-optic modulators, or deflectors, which diffract the beam with an acoustic wave in the sample, modulated in frequency via a voltage-controlled oscillator. ${ }^{23.24}$

Tweezers will also be employed to displace a particle by one or more lattice constants from its equilibrium position. Hence also, the tweezers will be scanned 
through a fixed array of points across the field of view to induce patterns that are either commensurate or incommensurate with the equilibrium configuration of the colloidal crystal. Laser tweezers also will be used to measure the viscosity of the fluid. A particle is trapped and video images taken as it is translated in an oscillatory fashion through the field of view. The velocity just before the particle falls out of the trap is measured from the video record and, along with the known force and particle diameter, used to calculate the sample dynamic viscosity (or crystal shear modulus).

\section{Confocal}

Confocal microscopy is another research technique planned for implementation within the LMM. Three fluid physics experiments, $\mathrm{PH}^{\mathrm{A}} \mathrm{SE}-2, \mathrm{PCS}-2$, and LФCA, scheduled for the LMM will employ the technique to probe the interior structure of complex colloidal systems in order to produce detailed three dimensional models of the unique structures formed in microgravity. Figure 7 shows the kind of image that can be obtained with a confocal microscope.

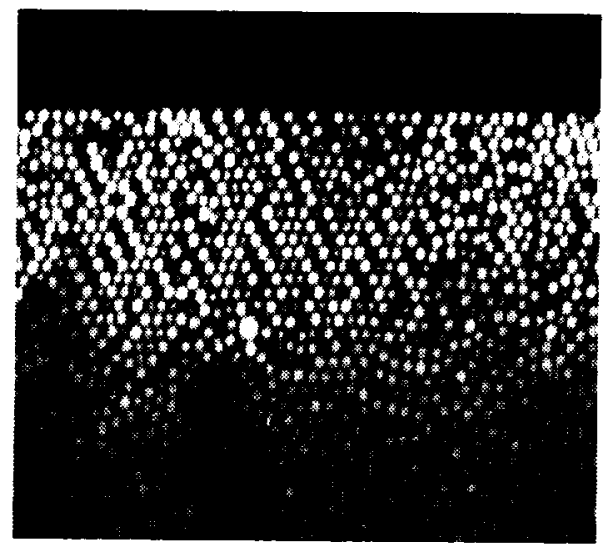

Figure 7: Two micron diameter PMMA spheres dyed with rhodamine ( $x-z$ slice). Taken with Leica laser scanning confocal microscope 100X Objective, 12.5 X Electronic Zoom.

Within the LMM, confocal microscopy will be implemented using a combination of commercial offthe-shelf subsystems, modified to allow non-standard operating configurations. The design involves a 532nm frequency-doubled Nd:YAG laser, a Yokogawa Model CSU10 Confocal Scanner, a Leica RXA upright microscope, and QImaging Retiga 1300, 12 bit digital CCD camera.

The Yokogawa CSU10 confocal unit used on the LMM is a Nipkow disk-based scanner (as opposed to a laser scanning device). The Nipkow disk version of confocal microscopy was chosen for the LMM due to its inherent stability, speed, and simplicity. It uses a spinning array of matched apertures and lenses to individually map regions of the sample onto the CCD array. The rotational speed of the scanner will allow 30 frames per second of confocal images to the CCD camera. The crystal three-dimensional structure is reconstructed by assembling the slices with an image analysis program, from which colloidal growth, structure, and dynamics can be measured. The confocal module will be attached to the LMM using slide rails, and will access the sample though an auxiliary port on the Leica RXA.

Confocal microscopy generally has advantages over other microscopy techniques such as phase contrast, differential interference contrast, and fluorescence due to the enhanced rejection of out-of-focus light provided by the confocal technique. Confocal is normally used on a fluorescent-dyed sample. It results in a much finer resolution in the sectioning dimension (through the sample), allowing better reconstruction of crystal structure and lattice positions, even within somewhat turbid samples. The data is acquired by focusing at the near side of the sample and scanning a two-dimensional image at each focal plane as the focus is translated through to the far side of the sample. ${ }^{15}$

\section{Spectrophotometry}

The spectrophotometer diagnostic capability will measure the photonic properties of crystals grown in the microscope sample cells. Different crystal and alloy structures have various spectral transmission characteristics, which can be analyzed using this technique. The photonic samples will be transilluminated over a range of wavelengths, some of which will transmit through the sample with both a different intensity and at a different scattering angle. The static light scattering distribution will be detected with a high resolution Qlimaging Retiga $1300 \mathrm{CCD}$ array.

The spectrophotometer monochromatic input will be coupled to the epi-illumination port on the LMM microscope. Spectrophotometry will be implemented using the Metal Halide lamp in epiillumination, a monochrometer for visible wavelength discrimination, a translating pinhole in the aperture plane, and the 12 bit digital QImaging Retiga 1300 CCD camera. The monochrometer is used to select narrow-band visible light ( $10 \mathrm{~nm}$ bandwidth) from the collimated light in the epi-illumination path and pass it to the pin hole and on to the sample. The translating pinhole is planned to be adjustable in the $\mathrm{X}$ and $\mathrm{Y}$ directions to vary the angle of incidence (up to 
\pm 65 degrees for normal incidence angle) at the sample. Since this technique is looking at the reflected light coming back from the sample, the detector will be seeing the stop bands of the photonic crystals. When the monochrometer is tuned to a wavelength that is in the pass band of the photonic crystal, the light will pass through the crystal and only non-specular reflection will reach the detector.

\section{SUMMARY}

The LMM is a sophisticated, modified commercial research imaging light microscope with laser diagnostics hardware and interfaces to conduct on-orbit colloid, fluid physics, and biological experiments, creating a one-of-a-kind, state-of-the-art microscopic research facility. There are currently four fluid physics experiments planned to be the first to use the facility. The LMM provides imaging techniques of color video microscopy, bright field, dark field, phase contrast. differential interference contrast (DIC), interferometry, confocal microscopy, and spectrophotometry all combined in a single configuration. Integrated with the diagnostics are single-trap scanning laser tweezers, to perform sample particle manipulation and patterning.

The experiment-unique sample cells, procedures, and any specialized measurements (e.g., cell instrumentation, special light source, etc.) are customized within the constraints of the LMM, FIR, and ISS for each Principal Investigator. Such an arrangement allows cost and time savings on each experiment by reusing modular facility test equipment, rather than the traditional approach of designing standalone experiments for each Principal Investigator.

\section{REFERENCES}

1. F. Gati and M. Hill, "The FCF Fluids Integrated Rack: Microgravity Fluid Physics Experimentation on Board the ISS." AIAA-2001-4926 (October 2001).

2. R. Zurawski, "The ISS Fluids and Combustion Facility: Microgravity Combustion Science and Fluid Physics Research Capability," AIAA-2001-4925 (October 2001).

3. J.R. Brown, W.S. Chang, K.P. Hallinan, and H.C. Chebaro, "Heat Transfer from Stable Evaporating Thin Films in the Neighborhood of a Contact Line," Proceedings of National Heat Transfer Conference, Atlanta, GA, 93-HT-4, (1993).

4. J. Huang, M. Karthikeyan, J. Plawsky, P. Wayner, Jr., "Constrained Vapor Bubble Heat Exchanger,"
Proceedings of 11 th International Heat Transfer Conference, Vol. 6, (August 23-28, 1998).

5. S. DasGupt, J. Plawsky, P. Wayner, Jr., "Interfacial Force Field Characterization in a Constrained Vapor Bubble Thermosyphon," AIChE Journal. Vol. 41. No. 9. (September 1995).

6. P.C. Wayner, Jr., "The Effect of Interfacial Mass Transport on Flow in Thin Liquid Films," Coll. and Surfaces. Vol. 52. p. 71, (1991).

7. P.C. Wayner, Jr., "Effect of Thin Film Heat Transfer on Meniscus Profile and Capillary Pressure," AIAA Journal, Vol. 17, pp. 772-776, (1979).

8. M.P. Doherty, C.T. Lant. and J.S. Ling. "The Physics of Hard Spheres Experiment on MSL-1: Required Measurements and Instrument Performance," AIAA-980462, (1998).

9. W.B. Russel, D.A. Seville, and W.R. Schowalter. "Colloidal Dispersions," Cambridge U. Press, Cambridge. (1995).

10. P.M. Chaikin and T.C. Lubensky, "Principles of Condensed Matter Physics," Cambridge U. Press. Cambridge (1995).

11. R.R. Ansari, E.A. Hovenac, S. Sankaran, J.M. Koudelka, D.A. Weitz, L. Cipelletti, and P.N. Segre, "Physics of Colloids in Space Experiment." Space Technology and Applications International Forum - STAIFF-99, (1999).

12. J. Zhu, M. Li. R.B. Rogers, W.V. Meyer, R.H. Ottewill, STS-73 Space Shuttle Crew, W.B. Russel, and P.M. Chaikin, "Crystallization of Hard Sphere Colloids in Microgravity," Nature (London), 387, 883-885, (1997).

13. D.A. Weitz, P.N. Pusey, and R.R. Ansari, "Colloidal Gelation (CGEL) I Year Report (unpublished)," (July 15, 1998).

14. D.A. Weitz, P.N. Pusey, and R.R. Ansari. "Binary Colloid Alloy Test (BCAT) I Year Report (unpublished)," (March 24, 1998).

15. T. Biben, P. Bladon, and D. Frenkel, "Depletion Effects in Binary Hard-Sphere Fluids." J Phys-Condens Mat 8, 10799-10821 (1996).

16. P. Pouilin, H. Stark, T.C. Lubensky and D.A. Weitz, "Novel Colloidal Interactions in Anisotropic Fluids," Science 275, 1770, (1997). 
17. T. Gisler, R.C. Ball, and D.A. Weitz, "Strain Hardening of Fractal Colloid Gels," Phys. Rev. Letter 82: 1064, (1999).

18. A.D. Dinsmore, J.C. Crocker, A.G. Yodh, "Self Assembly of Colloidal Crystals," Curr Opin Colloid Interface Sci 3. 5-11. (1999).

19. M.P. Doherty, S.M. Motil, J.H. Snead, and D.C. Malarik, "Microscope-Based Fluid Physics Experiments in the Fluids and Combustion Facility on ISS," Spacebound 2000, Vancouver, B.C. (May 2000).

20. P.D. Kaplan. J.L. Rouke. A.G. Yodh. and D.J. Pine, "Entropically Driven Surface Phase Separation in Binary Colloidal Mixtures," Phys. Rev. Letter 72: (4) 582-585, (1992).
21. S. Inoue, Video Microscopy. Plenum Press, New York and London, (1986).

22. R.B. Rogers, "Physical Modeling of Materials Science Phenomena Using Hard-Sphere Colloidal Suspensions," MS Thesis, Case Western Reserve University, (2000).

23. D.W. Griffin, M.P. Doherty, and D.C. Malarik, "Micromanipulation for Microgravity Fluid Physics Research," Nanospace 2000 Conference. Houston. TX, (2000).

24. A. Ashkin, "Acceleration and Trapping of Particles by Radiation Pressure," Physical Review Letters, 24. 156-159. (1970). 


\section{REPORT DOCUMENTATION PAGE}

Public reporting burden for this collection of information is estimated to average 1 hour per response, including the time for reviewing instructions, searching existing data saurces, gathering and maintaining the data needed, and completing and reviewing the collection of information. Send comments regarding this burden estimate or any other aspect of this collection of information, including suggestions for reducing this burden, to Washington Headquarters Services, Directorate for Information Operations and Davis Highway. Suite 1204, Arlington, VA 22202-4302, and to the Office of Management and Budget, Paperwork Reduction Project (0704-0188), Washington, DC 20503.

\begin{tabular}{|l|l|r|}
\hline 1. AGENCY USE ONLY (Leave blank) & $\begin{array}{r}\text { 2. REPORT DATE } \\
\text { February } 2002\end{array}$ & $\begin{array}{r}\text { 3. REPORT TYPE AND DATES COVERED } \\
\text { Technical Memorandum }\end{array}$ \\
\hline
\end{tabular}

\section{TITLE AND SUBTITLE}

2002

5. FUNDING NUMBERS

The Light Microscopy Module: An On-Orbit Multi-User Microscope Facility

6. AUTHOR(S)

Susan M. Motil and John H. Snead

7. PERFORMING ORGANIZATION NAME(S) AND ADDRESS(ES)

National Aeronautics and Space Administration

John H. Glenn Research Center at Lewis Field

Cleveland, Ohio 44135-3191

WU-400-32-3C-00

9. SPONSORING/MONITORING AGENCY NAME(S) AND ADDRESS(ES)

National Aeronautics and Space Administration

Washington, DC 20546-0001

8. PERFORMING ORGANIZATION REPORT NUMBER

$E-13060$

Prepared for the International Space Station Utilization-2001 sponsored by the American Institute of Aeronautics and Astronautics, Cape Canaveral, Florida, October 15-18, 2001. Responsible person. Susan M. Motil, organization code 6728, 216-433-8589.

\section{2a. DISTRIBUTION/AVAILABILITY STATEMENT}

12b. DISTRIBUTION CODE

Unclassified - Unlimited

Subject Categories: 35 and 74

Distribution: Nonstandard

Available electronically at hup://gltrs.grc.nasa.gov/GLTRS

This publication is available from the NASA Center for AeroSpace Information, 301-621-0390.

13. ABSTRACT (Maximum 200 words)

The Light Microscopy Module (LMM) is planned as a remotely controllable on-orbit microscope subrack facility, allowing flexible scheduling and operation of fluids and biology experiments within the Fluids and Combustion Facility (FCF) Fluids Integrated Rack (FIR) on the International Space Station (ISS). The LMM will be the first integrated payload with the FIR to conduct four fluid physics experiments. A description of the LMM diagnostic capabilities, including video microscopy, interferometry, laser tweezers, confocal. and spectrophotometry, will be provided.

14. SUBJECT TERMS

Microscopy; Colloid physics; Laser tweezers; Spectrophotometry; Confocal microscopy

17. SECURITY CLASSIFICATION OF REPORT

Unclassified
18. SECURITY CLASSIFICATION OF THIS PAGE

Unclassified
19. SECURITY CLASSIFICATION OF ABSTRACT

Unclassified

NSN 7540-01-280-5500

15. NUMBER OF PAGES

14

16. PRICE CODE

20. LIMITATION OF ABSTRACT

Standard Form 298 (Rev. 2-89) Prescribed by ANSI Std. Z39-18 298-102 